\title{
Report on Eighteen Cases Treated with Sodium Gynocardate.
}

\author{
MARIE WARDMANN, \\ E. LANDEMANN.
}

Early in 1928, Sir Leonard Rogers kindly sent samples of alepol and sodium gynocardate (Martindale's " C " Fraction) to the Bankura Leper Home for trial. Dr. Cochrane, who was then in medical charge of the latter home, sent a sample of the sodium gynocardate to us for trial. Owing to the illness of one of us (E. L.), this experiment was postponed for some months. The following is a short report (tabulated) of a series of eighteen cases treated over a period of six months (shortest) to 15 months (longest) :-

\begin{tabular}{cccccccc}
\hline \hline \multicolumn{2}{c}{ Cases. } & S. & I. & G.I. & S.F. & W. & D. \\
A1 & 4 & 0 & 3 & 1 & 0 & 0 & 0 \\
B1 & 1 & 0 & 1 & 0 & 0 & 0 & 0 \\
B2 & 4 & 0 & 4 & 0 & 0 & 0 & 0 \\
B3 & 5 & 0 & 2 & 2 & 0 & 1 & 0 \\
A2 & 4 & 0 & 2 & 0 & 0 & 2 & 0 \\
\cline { 2 - 7 } & -18 & 0 & 12 & -3 & -1 & -1 & 0 \\
\hline \hline
\end{tabular}

It is interesting to compare these results with those obtained from the use of alepol, which were reported in Leprosy Notes, No. 5, April, 1929. The comparison is as follows :-

\begin{tabular}{|c|c|c|c|c|c|c|}
\hline Cases. & S. & I. & G.I. & S.F. & W. & D. \\
\hline A1 9 & 1 & 1 & 6 & 1 & 0 & 0 \\
\hline B1 3 & 1 & 0 & 2 & 0 & 0 & 0 \\
\hline B2 5 & 0 & 0 & 4 & 1 & 0 & 0 \\
\hline B3 7 & 0 & 0 & 6 & 0 & 0 & 1 \\
\hline - & - & - & - & - & - & - \\
\hline 24 & 2 & 1 & 18 & 2 & 0 & 1 \\
\hline
\end{tabular}

S.= Stationary ; I.= Improved ; G.I.= Greatly improved ; S.F.= Sympton free; W. = Worse ; D.= Dead.

(Although it is impossible to draw definite conclusions from so small a series of cases, it can be stated that alepol appears to have a distinct advantage over sodium gynocardate. Subsequent reports from writers on the field tend to confirm this.-EDitor.) 